Gut, 1984, 25, 665-672

\title{
Natural history of recurrent Crohn's disease at the ileocolonic anastomosis after curative surgery
}

\author{
P RUTGEERTS, K GEBOES, G VANTRAPPEN, R KERREMANS, \\ J L COENEGRACHTS, AND G COREMANS
}

From the Department of Medicine, Division of Gastroenterology, Departments of Pathology, and Surgery, University Hospital, Leuven, Belgium

SUMmaRY An endoscopical and histological study was carried out in 114 patients, treated by 'curative' resection of the terminal ileum and part of the colon for Crohn's disease, in order to study the natural history of recurrent Crohn's disease. The recurrence rate of Crohn's disease in patients examined within one year of the operation was $72 \%$. This figure did not differ significantly from that in patients examined one to three years or three to 10 years after surgery ( $79 \%$ and $77 \%$ respectively). Recurrence was located in the neoterminal ileum and at the anastomosis in $88 \%$ of the patients. Early endoscopic signs of recurrence were small aphthous ulcers in the neoterminal ileum. Ileal biopsies at this stage showed an important inflammatory cell infiltrate of the lamina propria with numerous eosinophils and fusion and blunting of the villi. More advanced lesions observed in patients examined one to three years after surgery, consisted of larger, often serpiginous ulcerations and nodular thickening of folds. In patients examined three to 10 years after the operation, the anastomosis was frequently stenosed and rigid, with large ulcers extending from the stenosis into the colon. Mucosal granulomas may be found in normal appearing mucosa as well as in the obviously inflamed mucosa surrounding the ulcers. These studies suggest that recurrence of Crohn's disease almost always develops in the first year after the operation. Significant endoscopic lesions may be present without clinical symptoms, particularly in the earlier stages of the disease.

The recurrence rate of Crohn's disease after curative resection of the terminal ileum and part of the colon varies from $17 \%$ to $81 \%$ in different reports. ${ }^{1-4}$ This wide variation is not surprising as the criteria used to diagnose recurrence are highly variable. Recurrence of clinical symptoms, the presence of objective signs of recurrence on radiological or pathological examination, and necessity of a surgical reintervention, have all been used as criteria for recurrent disease. The overall recurrence rate is reported to be lower in patients with Crohn's colitis than in those operated upon for small bowel disease..$^{5-7}$

Recurrence of Crohn's disease frequently leads to repeated surgical procedures ${ }^{8}$ and it has been shown that the mortality rate increases with the years of evolutive diseases. ${ }^{9}$

The recurrence rate of Crohn's disease is reported

Address for correspondence: Professor G Vantrappen. Department of Medicine. University Hospital St Rafael. University of Leuven. Leuven. Belgium.

Received for publication 22 July 1983 to increase with the years of follow up after surgery. ${ }^{610} 11$ Few data are available, however, on the evolution of recurrent Crohn's disease. As recurrent lesions tend to be located in the region of the anastomosis, which can easily be reached by colonoscopy, endoscopic and histopathological studies seem to offer the best approach to study recurrent disease.

The main aim of this investigation was to study the natural history of recurrent Crohn's disease by means of endoscopic examinations in patients who had been treated by a curative bowel resection - that is, in whom all macroscopically diseased tissue had been resected.

\section{Methods}

PATIENTS

From October 1980 to April 1982, 114 patients who had been treated by 'curative' resection of the terminal ileum and part of the colon for Crohn's 
disease cooperated in the study. They represent $69 \%$ of the 165 patients in whom a curative resection had been carried out in the 10 year period before the study. There were 56 men and 58 women, aged 17 to 62 years. Ninety seven patients $(85 \%)$ had been operated upon once, $12(11 \%)$ twice and five (4\%) three times. The time interval since the last operation varied from eight weeks to 10 years, with a median value of 72 months. The ileum had been anastomosed to the right colon in $89 \%$, and to the left colon in $11 \%$ of the patients. The operations had all been carried out by the same surgical team for complications of Crohn's disease, involving the ileum alone in 41 patients $(36 \%)$ and the ileum and right colon in 58 patients $(51 \%)$. In these two groups of patients, ileum, and right hemicolon were resected and an ileotransversal anastomosis was constructed. In 15 patients $(13 \%)$ the colonic involvement extended into the left colon, and in these patients an ileosigmoidostomy (14) or an ileoproctostomy (1) was performed. At operation a segment of about 15 centimetres of macroscopically normal small bowel beyond the diseased ileal segment was always excised. Peroperative frozen section examination of the proximal and distal cut margins of the excised specimen was not carried out.

All patients operated upon during the 10 year period preceding the study were invited to cooperate. Only those who agreed with the examination and gave their informed consent were included in the study. Twenty nine of 32 patients $(91 \%)$, operated upon less than one year before the study, 24 of the 40 patients (60\%) operated between one and three years, and 61 of the 93 patients $(66 \%)$ operated between three to 10 years before the study were available for and consented in follow-up endoscopies.

In each patient, a colonoscopy with ileoscopy was performed using a CF-IB colonoscope (Olympus). The ileum was examined up to $40 \mathrm{~cm}$ above the anastomosis. The anastomosis was always carefully inspected; the expansion was evaluated as normal, slightly stenosed (allowing the colonoscope to be passed) and severely stenosed (not allowing passage of the colonoscope). The mucosal pattern of the colon and the neoterminal ileum was assessed and described as normal, thickened folds, or nodular pattern. The presence of mucosal defects was noted and the size and shape of the ulcers was assessed. Ulcers were called 'aphthous' if they were small, punched out and mostly with hyperaemic slightly raised border. Large ulcers were described as oval, longitudinal or serpiginous. A diagnosis of recurrent Crohn's disease was based on the presence of endoscopically demonstrable mucosal defects (ulcerations), associated or not with other lesions such as nodules and stenosis. Hyperaemia and friability of the mucosa alone were not considered as signs of recurrence. Eighteen patients who had had an ileocolonic anastomosis after resection for colonic carcinoma were examined as a control group. Ileocolonoscopies were performed and biopsies taken in the same way as in the group of patients.

\section{PATHOLOGICAL EXAMINATION}

Two hundred and seventy eight endoscopic biopsy specimens of the neoterminal ileum taken in 114 patients were suitable for study. They were obtained with a classical forceps (7Fs) with oval jaws and central needle (ACMI) in endoscopically normal mucosa as well as in the reddened mucosa in close proximity of ulcers. Another 326 biopsies were taken at various levels throughout the postanastomotic colon. The tissue was fixed in Bouin's solution, embedded in paraffin wax, sectioned and stained with haematoxylin and eosin. All ileal mucosal biopsies were coded and scored without knowledge of endoscopic findings. Nine to 16 different sections of each biopsy specimen were examined using 11 histopathologic criteria relative to inflammation. These included the presence of ulcerations, villous height and villous/crypt ratio, epithelial regeneration and/or nuclear atypia, cryptitis, oedema of the lamina propria, the presence of lymphangiectasia, lymphoid hyperplasia, submucosal inflammation, and increased mucus secretion. The biopsies were interpreted by the pathologist using the following classification. A diagnosis of specific ileitis was based on the presence of granulomas. Non-specific ileitis was diagnosed when inflammatory changes without specific characteristics were present. If no pathological changes were found, the biopsy was considered to be normal. The colonic biopsies were studied for the presence of classical histological signs of Crohn's disease as described for endoscopic biopsies. ${ }^{12}{ }^{13} \mathrm{In}$ addition, the surgical specimens of all patients were reexamined. At least three, usually four biopsies were taken in various areas of the resected ileum and colon, and the number of granulomas in each section was counted. The cut ends of the resected bowel segments were also reexamined in order to detect even small foci of inflammation.

In order to evaluate the importance and significance of the microscopic findings, the endoscopic ileal biopsies of the control series of 18 patients who had had an ileocolonic anastomosis after surgery for carcinoma were studied. In all patients with Crohn's disease and in the controls the mean villous height was assessed in well orientated ileal specimens in which three longitudinally 
sectioned villi were measured. Measurements were performed with a scale on a Leitz visor at $\times 100$.

\section{Results}

The crude recurrence rate of Crohn's disease in the 114 patients amounted to $77 \%$. This is not the true incidence in all patients operated upon in the period of 10 years preceding the study as 51 patients did not cooperate or were not available for follow up endoscopy. The incidence of recurrent Crohn's disease amounted to $72 \%$ of the 29 patients examined within one year of the curative resection, $79 \%$ of the 24 patients examined one to three years after surgery and $77 \%$ of the 61 patients examined more than three years after surgery. These incidence rates are not significantly different from each other.

Recurrent disease was endoscopically confined to the neoterminal ileum and the anastomosis in $88 \%$ $(100 / 114)$ of the patients. No relation was found between the incidence of recurrence and any of the following factors: age, sex, duration of disease before surgery, localisation of disease or length of resected ileal segment (Table 1 ).

Granulomas were present in $78 \%$ of the 114 specimens of resected ileum. The number of granulomas per section in the operative specimens, however, was small $(1 \cdot 2)$. The section margins of the ileal as well as of the colonic side were free of granulomas and of inflammatory changes in all but nine patients.

No relation was found between the presence of granulomas in the operative specimen, or inflammatory changes in the cut margins, and the incidence of recurrence in any of the groups (Table 2).

The relation between recurrence of symptoms and objective endoscopic evidence of recurrence was poor. Both symptoms and endoscopic mucosal defects, were present in $39 \%$ and absent in $15 \%$ of the patients. In $42 \%$ of the patients, mostly operated upon less than three years before the study, there were endoscopic signs of recurrence without symptoms, and in $4 \%$ symptoms occurred without endoscopic evidence of recurrence.

The natural history of recurrent Crohn's disease
Table 2 Relation between recurrence rate of Crohn's disease and histologic data of the operative specimens

\begin{tabular}{llll}
\hline & Patients & $\begin{array}{l}\text { Granulomas in } \\
\text { resected ileum }\end{array}$ & $\begin{array}{l}\text { Inflammatory changes } \\
\text { in the cut margins }\end{array}$ \\
\hline Recurrence & 87 & $76(66 \%)$ & $7(8 \%)$ \\
No recurrence & 27 & $13(48 \%)$ & $2(7.4 \%)$ \\
\hline
\end{tabular}

was studied by systematic comparison of endoscopic and microscopic lesions observed at different times after the operation. Endoscopic observations are summarised in Fig. 1. In the 29 patients examined less than one year after the operation the earliest finding was hyperaemia, mostly patchy, and friability of the mucosa. As different observers may interpret such lesions in a different, non-reproducible manner, these alterations were not considered as signs of recurrence. Small punchedout (aphthous) ulcers were considered to constitute the first objective sign of recurrent disease. Aphthous ulcers were present as the only lesion in $76 \%$ of the 21 patients with recurrent disease in the first year after the operation. Four patients had only one or a few aphthous ulcers, with normal mucosa between the ulcers. In nine patients numerous ulcers were present and in three the neoterminal ileum was studded with ulcers (Figs. 2a, b). These aphthous ulcers were often located at the crest of thickened folds. In some patients the aphthous ulcers occurred in clusters or in a linear array. In all patients with early recurrence, the anastomosis was wide open and the site of the anastomosis was only detected by the change in mucosal colour and pattern. More severe lesions - that is, nodules and large ulcers, were present in only five patients $(24 \%)$ and were not prominent. Stenosis of the ileocolonic anastomosis was never observed at this stage of recurrence. In most of the 24 patients examined one to three years after curative resection, more advanced lesions were observed. The most prominent picture $(53 \%)$ consisted of nodules, isolated or on thickened folds, separated by larger, mostly linear or serpiginous, seldom oval or longitudinal ulcers (Fig. 2c). At this stage of the disease

Table 1 Relation between recurrence rate of Crohn's disease and different clinical parameters of the disease before the operation

\begin{tabular}{|c|c|c|c|c|c|c|c|}
\hline & Patients & Females & Males & $\begin{array}{l}\text { Duration of the disease } \\
\text { (months - range) }\end{array}$ & $\begin{array}{l}\text { Localisation } \\
\text { lleitis }\end{array}$ & $\begin{array}{l}\text { of disease } \\
\text { Ileocolitis }\end{array}$ & $\begin{array}{l}\text { Length of resected } \\
\text { Segment }(\mathrm{cm})\end{array}$ \\
\hline $\begin{array}{l}\text { Recurrence } \\
\text { No recurrence }\end{array}$ & $\begin{array}{l}87 \\
27\end{array}$ & $\begin{array}{l}46 \\
12\end{array}$ & $\begin{array}{l}41 \\
15\end{array}$ & $\begin{array}{l}64(0-221) \\
84(0-292)\end{array}$ & $\begin{array}{l}29(33 \%) \\
12(44 \%)\end{array}$ & $\begin{array}{l}58(67 \%) \\
15(56 \%)\end{array}$ & $\begin{array}{l}37(20-100) \\
44(15-120)\end{array}$ \\
\hline
\end{tabular}




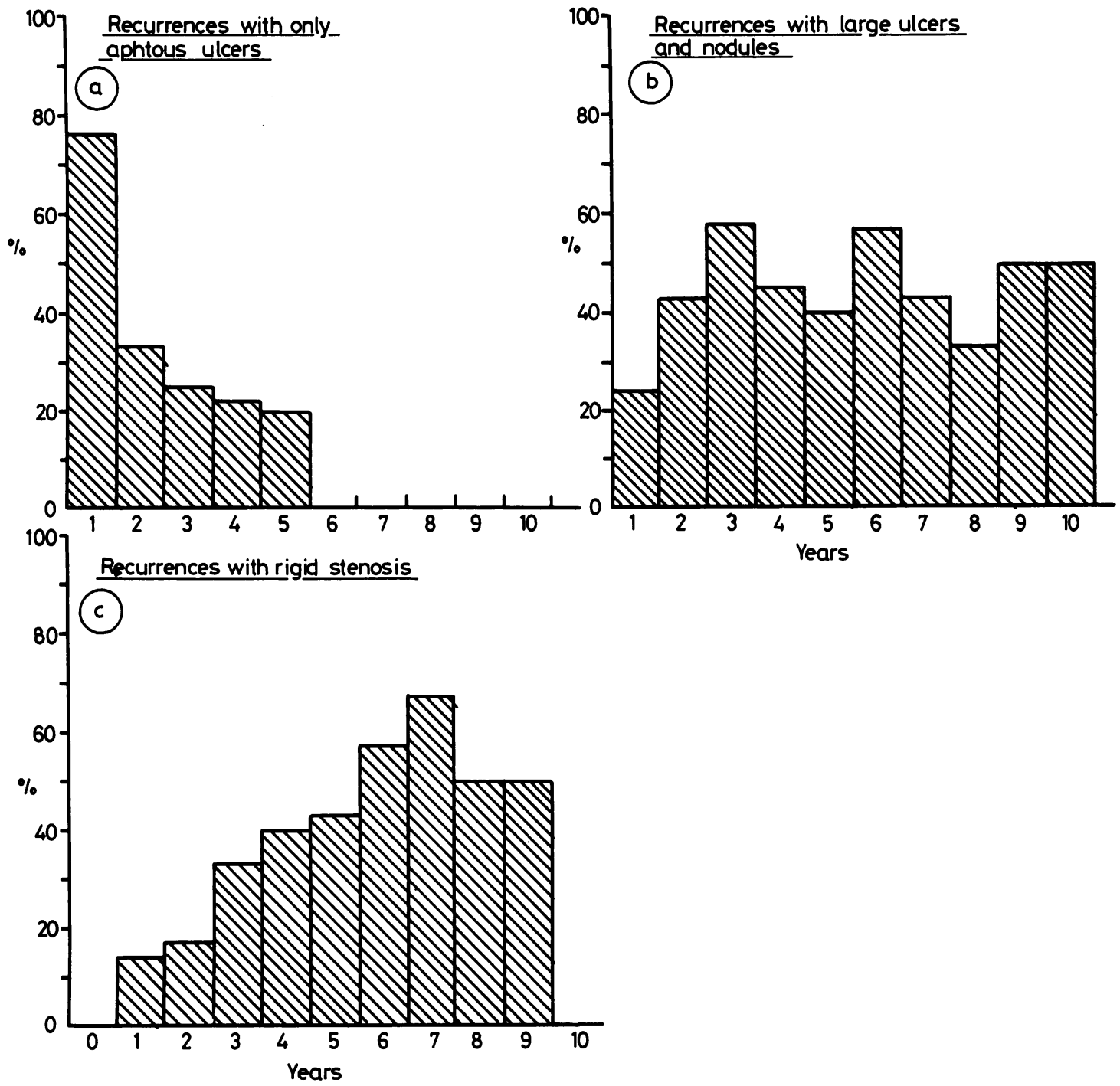

Fig. 1 (a) Percentage of patients presenting with aphthous ulcers in neoterminal ileum as only endoscopic sign of recurrence in relation to interval between surgery and follow-up endoscopy.

(b) Percentage of patients presenting with more severe lesions - that is, large ulcers and nodules.

(c) Percentage of patients presenting with rigid stenosis of ileocolonic anastomosis.

the anastomosis was slightly narrowed but could still be passed by the colonoscope in most cases. Mild lesions - that is, only aphthous ulcers were still present in $32 \%$ of these patients and a rigid stenosis (not allowing passage of the endoscope) of the ileocolonic anastomosis had already developed in $15 \%$ of the patients.

In $46 \%$ of the 61 patients examined more than three years after surgery, the recurrence of Crohn's disease was characterised by a rigid ulcerated stenosis of the ileocolonic anastomosis and/or the neoterminal ileum, which could not be passed by the colonoscope (Fig. 2d). From the stenotic area large serpiginous or longitudinal ulcers extended into the post-anastomotic colon in 10 patients $(16 \%)$. In three patients (5\%) aphthous ulcers were the only abnormality seen at endoscopy four years after the operation. 

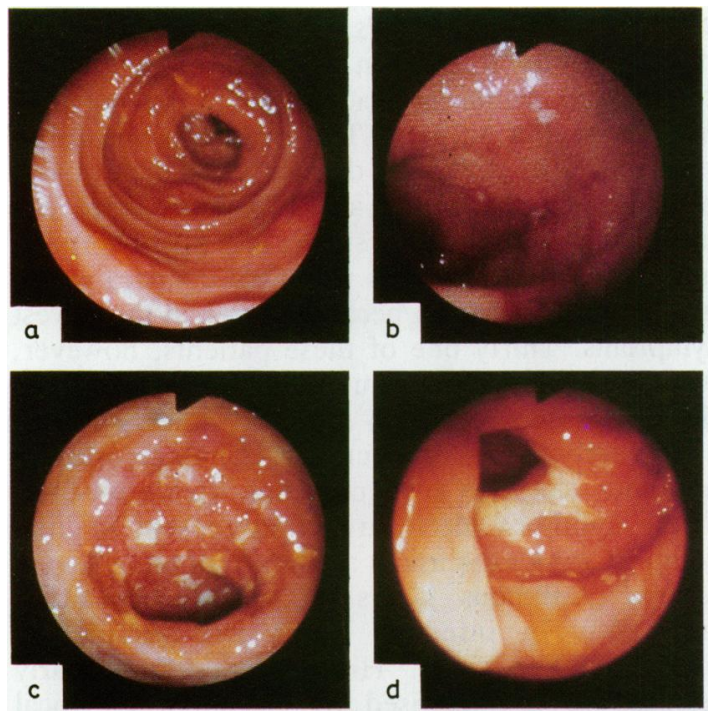

Fig. 2 (a) Early recurrence of Crohn's disease (four months after curative surgery): one aphthous ulcer is present in the neoterminal ileum.

(b) Early recurrence: mulitple isolated aphthous ulcers are present.

(c) Recurrent Crohn's disease at ileocolonic anastomosis in evolution: neoterminal ileum is studded with larger oval ulcers.

(d) Evolution of recurrent Crohn's disease at the ileocolonic anastomosis five years after surgery has led to rigid stenosis. Large serpiginous ulcers irradiate from anastomosis into postanastomotic colon.

\section{HISTOLOGIC EXAMINATION OF ENDOSCOPIC}

BIOPSIES

Ileal biopsies obtained at endoscopy are usually quite small and mostly contain only mucosa. In this study about $10 \%$ of the specimens were inadequate for histologic interpretation. Comparison of endoscopic and histologic observations (Table 3) indicates that the results obtained by the two different techniques correlate fairly well. The ileum was found to be normal on endoscopy in 27 patients; 19 of these patients had no histologic signs of inflammation. A specific histological diagnosis, based upon the presence of typical granulomas (Figs. 3, 4), was obtained in 13 patients $(11 \%)$; three of these patients had a neoterminal ileum that appeared normal at endoscopy. Microgranulomas that is, a collection of epitheloid cells, were present in another six patients (5\%), but these were not considered as diagnostic. The biopsies of 76 patients showed various signs of severe inflammatory lesions. The most important findings in these patients were the presence of ulcerations (granulation tissue,
Table 3 Comparison of endoscopic and histologic data in patients after curative surgery for Crohn's disease

\begin{tabular}{|c|c|c|c|c|}
\hline \multirow[b]{2}{*}{ Patients } & \multirow[b]{2}{*}{ Endoscopic data } & \multicolumn{3}{|c|}{ Histologic data } \\
\hline & & Normal & $\begin{array}{l}\text { Aspecific } \\
\text { changes }\end{array}$ & Granulomas \\
\hline \multirow{6}{*}{$\begin{array}{l}<1 \text { year } \\
\text { after surgery } \\
(n=29) \\
1-3 \text { years } \\
\text { after surgery } \\
(n=24) \\
>3 \text { years } \\
\text { after surgery } \\
(n=61)\end{array}$} & $\begin{array}{l}\text { Recurrence } 21 \\
(72 \%)\end{array}$ & 2 & 18 & 1 \\
\hline & Normal $8(28 \%)$ & 7 & 0 & 1 \\
\hline & $\begin{array}{l}\text { Recurrence } 19 \\
(79 \%)\end{array}$ & 2 & 15 & 2 \\
\hline & Normal $5(21 \%)$ & 3 & 1 & 1 \\
\hline & $\begin{array}{l}\text { Recurrence } 47 \\
(77 \%)\end{array}$ & 1 & 39 & 7 \\
\hline & Normal $14(23 \%)$ & 9 & 4 & 1 \\
\hline \multirow[t]{2}{*}{$\begin{array}{l}\text { Total } \\
(n=114)\end{array}$} & $\begin{array}{l}\text { Recurrence } 87 \\
(77 \%)\end{array}$ & 5 & 72 & 10 \\
\hline & Normal $27(23 \%)$ & 19 & 5 & 3 \\
\hline
\end{tabular}

aphthous or fissuring ulcers) in $58(75 \%)$, blunting and irregularity of the villi in $72(94 \%)$ and severe focal non-specific inflammatory changes in all 76 patients. It may be reemphasised that biopsies were obtained in macroscopically non-ulcerated tissue. Similar lesions were never observed in the control series of patients with ileocolonic anastomosis for cancer. Villous atrophy, blunting and irregularity of the villi, and non-specific inflammatory lesions were most prominent in patients who underwent surgery more than one year before the examination. In patients in whom surgery had been performed less than one year before the endoscopic evaluation, normal specimens were seen more frequently $(31.6 \%$ of the specimens), while ulcerations occurred less frequently ( $7 \cdot 8 \%$ of the specimens). When present, the inflammatory infiltrate was patchy or focal in distribution. In $25 \%$ of the specimens obtained in early lesions, it was mainly composed of eosinophils. In advanced lesions the infiltrate was more mixed with an increase of neutrophylic polymorphs, lymphocytes, plasma cells, and lamina propria macrophages. The villous height was significantly decreased in patients with recurrent Crohn's disease as compared with patients with ileocolonic anastomosis for colonic cancer (Table 4).

Endoscopic biopsies of the postanastomotic colon showed the presence of granulomas in 18 patients, 10 of whom had an endoscopically 'normal' postanastomotic colon. Important aspecific inflammation was present in 31 patients; in 25 of them the postanastomotic colon appeared normal at endoscopy. In 65 patients biopsies in the postanastomotic colon showed no or minimal changes; all 65 patients had normal colonoscopies. 
Table 4 Villous height (in $\mu \mathrm{m}$ ) in patients with recurrent Crohn's disease as compared with patients with ileocolonic anastomosis for colonic cancer

\begin{tabular}{llll}
\hline & $\begin{array}{l}\text { Villous height } \\
(\mu \mathrm{m})\end{array}$ & $S D$ & Significance $(p)$ \\
\hline $\begin{array}{l}\text { Colonic cancer } \\
\begin{array}{l}\text { Recurrence }<\text { 1 year } \\
\text { after resection }\end{array}\end{array}$ & 474 & 26.4 & - \\
$\begin{array}{l}\text { Recurrence 1-3 years } \\
\text { after resection }\end{array}$ & 310 & 33.6 & $<0.001$ \\
$\begin{array}{c}\text { Recurrence }>3 \text { years } \\
\text { after operation }\end{array}$ & 379 & 14.7 & $<0.001$ \\
\hline
\end{tabular}

\section{Discussion}

The most important finding of this endoscopical and histological study of the ileocolonic anastomosis after curative resection for Crohn's disease, is that recurrence almost always develops within one year of the operation. The recurrence rate late after operation is no different from that during the first postoperative year. Clinical manifestations of the disease, however, are often absent in the early stage of recurrence. These recurrences are usually not detected as they are asymptomatic, and radiological examinations do not easily show these minimal mucosal alterations. These data suggest that the cause of recurrent Crohn's disease is probably not a metachronous aggression, ${ }^{14}$ because this would result in an increasing incidence of recurrence over the years after surgery. The overall incidence of recurrence of Crohn's disease is maybe overestimated in this study as 51 patients were not included in the follow up study. It is possible that a number of these patients were not cooperative or were lost to follow up because they had the fewest symptoms. Thirty one of these patients, however, were available for follow up but refused to undergo the colonoscopy.

The early lesions of recurrent Crohn's disease are aphthous ulcers in an hyperaemic friable mucosa. These aphthous ulcers are often present in ileocolonic Crohn's disease at a distance of more severe lesions. Aphthous ulcers as sole lesions occur frequently in infective ileitis and colitis, ${ }^{15} 16$ especially Yersiniosis. Histologically these early lesions are characterised by an important focal inflammatory cell infiltration with predominantly eosinophilic polymorphs. The focal aspect of inflammation in colonic Crohn's disease has been well recognised. ${ }^{14}$ The endoscopic finding that these aphthous ulcers occur in clusters or in a linear array suggests that confluence of these early lesions leads to the development of larger linear and serpiginous ulcers. In nearly half of the patients a rigid stenosis of the ileocolonic anastomosis had developed after a
Fig. 3 Biopsy in neoterminal ileum in patient with early recurrence of Crohn's disease (<one year). Two epitheliod granulomas ( $A, B$ arrows) are present in the lamina propria. Villi are irregular and blunt. An increased inflammatory infiltrate can be seen $(H E \times 60$ orig mag).

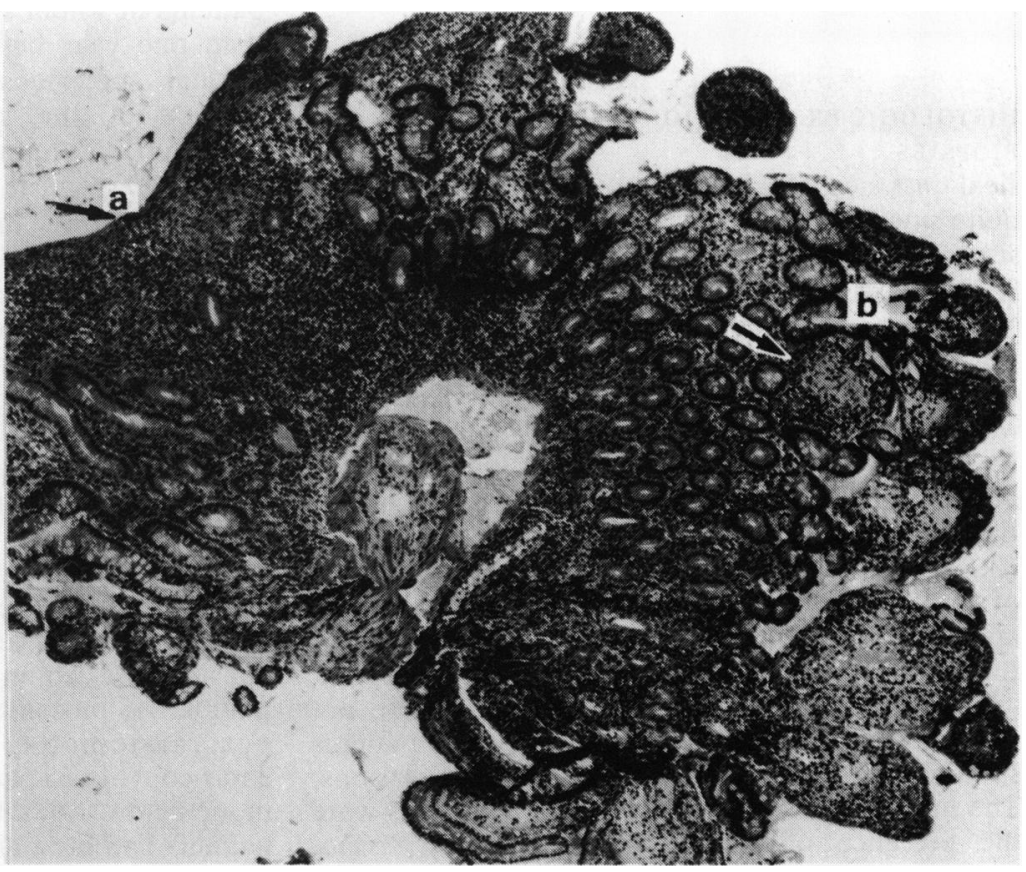


Fig. 4 (a) and (b) Details of the granulomas in the lamina propria.

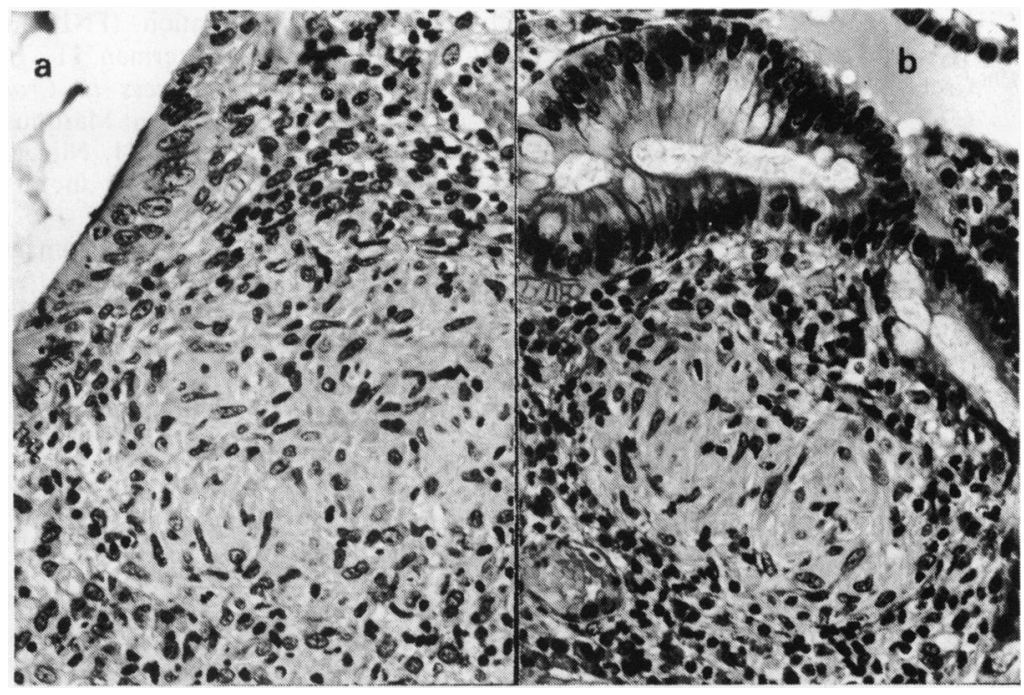

period of three or more years. Although the recurrence rate does not appear to increase over the years after operation, the lesions, however, become progressively more severe in the later phases: the histological abnormalities become much more pronounced, ulcers are more frequent, the inflammatory infiltrate is more severe and, in contrast to the biopsies of the early recurrences, normal mucosa is almost never observed; a significant decrease in villous height as compared with patients with ileocolonic anastomosis for cancer is also found. This is contrary to experimental findings ${ }^{18}$ but in agreement with the findings of others in man. ${ }^{19}$

In isolated cases an endoscopically normal neoterminal ileum contained aspecific inflammatory changes and even granulomas, which proves again that Crohn's lesions may remain microscopic without leading to macroscopic alterations or ulcerations. This occurred more frequently in the postanastomotic colon.

Marked differences have been reported in the recurrence rate of Crohn's disease in relation to the length of the involved segment, the age of the patients and the duration symptoms, ${ }^{6}$ and the sex of the patients. ${ }^{69}$ Such differences were not observed in the present study. This may be related to the method of evaluation, which allowed to obtain objective evidence of disease, even in the early stages of the recurrences.

The presence of inflammatory lesions in the cut ends of the resection specimens was not a predictive factor for the development of recurrent Crohn's disease. This observation confirms similar findings in earlier studies. Evidence is accumulating that frozen sections of the resection margin do not have a role in the surgical management of Crohn's disease. ${ }^{201}$

It has been suggested that the presence of granulomas in the resection specimen is associated with a lower recurrence rate ${ }^{2122}$ at least in the large bowel and anus. The present study does not confirm this observation for the iloeocolonic anastomosis and is in agreement with other observations that deny such a correlation. ${ }^{23} 24$

In the present study there is also a remarkable predilection for the neoterminal ileum as the site of recurrence, an observation made by some authors $^{25} 26$ and denied by others. ${ }^{27}$

\section{References}

1 Stahlgren LH, Ferguson LK. The results of surgical treatment of chronic regional enteritis. JAMA 1961; 175: 986-9.

2 Lennard-Jones JE, Stalder GA. Prognosis after resection of chronic regional ileitis. Gut 1967; 8: 332-6.

3 Atwell JD, Duthie HL, Goligher JC. The outcome of Crohn's disease. Br J Surg 1965; 52: 966-72.

4 Barber KW, Waugh JM, Beahrs OH, Sauer WG. Indications for and results of the surgical treatment of regional enteritis. Ann Surg 1962; 156: 472-82.

5 De Dombal FT, Burton I, Goligher JC. Recurrence of Crohn's disease after primary excisional surgery. Gut 1971; 12: 519-27.

6 Hellers G. Crohn's disease in Stockholm county 1955-1974. A study of epidemiology. Results of surgical treatment and long-term prognosis. Acta Chir Scand 1979; suppl 490: 31-48. 
7 Nugent FW, Malcolm C, Veidenheimer MC, Meissner WA, Haggitt RC. Prognosis after colonic resection for Crohn's disease of the colon. Gastroenterology 1973; 65: 398-402.

8 Greenstein AJ, Sachar DB, Pasternack BS, Janowitz HD. Reoperation and recurrence in Crohn's colitis and ileocolitis. Crude and cumulative rates. $N$ Engl J Med 1975; 293: 685-90.

9 Truelove SC, Pẽna AS. Course and prognosis of Crohn's disease. Gut 1976; 17: 192-201.

10 Felger L, Schenk HL. Recurrence in segmental enteritis following radical resection. Am J Surg 1940; 49: 307-21.

11 Keifer ED, Marshall SF, Brolsman MP. The management of chronic regional ileitis. Gastroenterology 1950; 14: 118-30.

12 Tytgat GN, Meuwissen S, Huibregtse K, Bartelsman J. Colonoscopy in inflammatory bowel disease. In: Rachmilewitz D, ed. Inflammatory bowel disease. The Hague, Boston, London: Martinus Nijhoff, 1982: 217-34.

13 Geboes K, Vantrappen G. The value of colonoscopy in the diagnosis of Crohn's disease. Gastrointestinal Endosc 1975; 22: 18-23.

14 Lee ECG, Papaioannou N. Recurrences following surgery for Crohn's disease. Clin Gastroenterol 1980; 9: 419-38.

15 Vantrappen G, Ponette E, Geboes K, Bertrand Ph. Yersinia enteritis and enterocolitis: gastroenterological aspects. Gastroenterology 1977; 72: 220-7.

16 Rutgeerts P, Geboes K, Ponette E, Coremans G, Vantrappen G. Acute infective colitis caused by endemic pathogens in Western Europe: endoscopic features. Endoscopy 1982; 14: 212-9.

17 Yardley JH, Hamilton SR. Focal non-specific inflam- mation (FNI) in Crohn's disease. In: Pēna AS, Weterman IT, Booth CC, Strober W, eds. Recent advances in Crohn's disease. The Hague, Boston, London: Martinus Nijhoff, 1981: 62-6.

18 Woo ZH, Nijgaard K. Small bowel adaptation after colectomy in rats. Scand J Gastroenterol 1978; 13: 903-10.

19 Bechi P, Romagnoli P, Cortesini C. Ileal mucosal morphology after total colectomy in man. Histopathology 1981; 5: 667-78.

20 Hamilton SR, Reese J, Pennington L, et al. No role of resection margin frozen sections in the surgical management of Crohn's disease. Gastroenterology 1982; 82: 1078.

21 Glass RE, Baker WNW. Role of the granuloma in recurrent Crohn's disease. Gut 1976; 17: 75-7.

22 Chambers TJ, Morson BC. The granuloma in Crohn's disease. Gut 1979; 20: 269-74.

23 Pennington L, Hamilton SR, Bayless TM, Cameron JL. Surgical management of Crohn's disease. Influence of disease at margin of resection. Ann Surg 1980; 192: 311-8.

24 Wolfson DM, Sachar DB, Cohen A, et al. Granulomas do not affect postoperative recurrence rates in Crohn's disease. Gastroenterology 1982; 83: 405-9.

25 Goligher JC. Inflammatory disease of the bowel. Results of resection for Crohn's disease. Dis Colon Rectum 1976; 19: 584-7.

26 Farmer RG, Hawk WA, Turnball RB. Clinical patterns in Crohn's disease. A statistical study of 615 cases. Gastroenterology 1975; 68: 627-35.

27 Koch TR, Cave DR, Ford H, Kirsner JB. Crohn's ileitis and ileocolitis. A study of the anatomical distribution of recurrence. Dig Dis Sci 1981; 26: 528-31. 